\title{
Pre-Exposure Prophylaxis (PrEP) in the Prevention of HIV: Strategies, Target Populations and Upcoming Treatments
}

This article was published in the following Dove Press journal: HIVIAIDS - Research and Palliative Care

\section{Ayșe Elif Özdener-Poyraz Malgorzata Slugocki Julie Kalabalik-Hoganson Jayoung Han}

Fairleigh Dickinson University, School of Pharmacy and Health Sciences, Department of Pharmacy Practice, Florham Park, NJ 07932, USA
Correspondence: Ayșe Elif Özdener-

Poyraz

Fairleigh Dickinson University, School of Pharmacy and Health Sciences,

Department of Pharmacy Practice, 230

Park Avenue, M-SpI-0I, Florham Park, NJ 07932, USA

$\mathrm{Tel}+973-443-82$ II

Email eozdener@fdu.edu

\begin{abstract}
Pre-exposure prophylaxis (PrEP) against HIV infection with tenofovir/emtricitabine is proven to be effective yet uptake of this preventive measure has been difficult due to several barriers such as cost, access, and misinformation. Certain subpopulations are disproportionately affected by this problem. Several methods have been developed to close the gap in care. New antiretroviral treatment strategies are being investigated for safety and efficacy in preventing HIV infection.
\end{abstract}

Keywords: pre-exposure prophylaxis, HIV prevention, PrEP uptake, medications

\section{Introduction}

Pre-exposure prophylaxis (PrEP) against human immunodeficiency virus (HIV) infection is recommended by the Centers for Disease Control and Prevention (CDC) for men who have sex with men (MSM), heterosexual men and women, and injection drug users at substantial risk of acquiring HIV infection. Substantial risk is defined as having an HIV-positive sexual partner, recent bacterial sexually transmitted infection (STI), high number of sex partners, history of inconsistent or no condom use, commercial sex work, HIV-positive injecting partner, or sharing injection equipment. ${ }^{1}$

Tenofovir disoproxil fumarate/emtricitabine (TDF/FTC) was the first drug to receive Food and Drug Administration (FDA) approval for PrEP against HIV infection in July 2012. Results from the iPrEX and Partners Prep studies led to its approval, and it is currently recommended by the CDC for PrEP against HIV infection. In October 2019, tenofovir alafenamide/emtricitabine (TAF/FTC) also received FDA approval for PrEP however the indication excludes those at risk from receptive vaginal sex. ${ }^{2}$ TAF/FTC for PrEP is not yet recommended in the United States (US) or European guidelines. ${ }^{1,3}$ PrEP with TDF/FTC reaches maximum protection levels at about 7 days of use for people engaging in receptive anal sex. For patients engaging in receptive vaginal sex, PrEP reaches maximum protective levels at 21 days. ${ }^{4}$

Recently published data shows that there are 1.2 million people at high risk for acquiring HIV infection in the US but there were only 8768 PrEP utilizers in 2012. In 2016 , this number increased to 77,120 which is a $73 \%$ increase in over a span of 4 years. States with the highest rate of PrEP use per 100,000 people were New York, Massachusetts, Rhode Island, Washington, and Illinois. Most PrEP users in 2016 were 
male and between the ages $25-44$ (93\% and 64\%, respectively), and in the same year, $81 \%$ of all new HIV diagnoses were in men. More than half (54\%) of all new diagnoses were ages 25-44 years. The South has the highest number of new HIV diagnoses compared to other regions of the country but has disproportionately lower number of people utilizing PrEP. More than half (52\%) of all new HIV diagnoses in 2016 occurred in the South but only $30 \%$ of all PrEP users were from this region. ${ }^{5}$ These values likely underestimate PrEP uptake in the US because there is no central database that collects this information. Instead, researchers collect this data from pharmacies, insurance claims, hospitals, outpatient facilities, and physicians' offices.

The World Health Organization (WHO) recommends PrEP for people at substantial risk of acquiring HIV infection as an additional preventive option. ${ }^{6}$ Globally, countries are at varying stages of PrEP uptake. It is estimated that there were 300,000 PrEP users in 2018 with most of them being in the US. ${ }^{7}$ A study conducted by UNAIDS showed that of the 69 countries that reported PrEP availability, 56 countries stated they had at least one barrier that limited patient access to PrEP. High out-of-pocket costs and PrEP only being provided in specialized HIV treatment locations were the top barriers to medication access. ${ }^{8}$

There is a gap in PrEP utilization with varying degrees of uptake in different countries. This narrative review article is intended to discuss strategies that have been used to increase PrEP utilization in the US, identify target populations in the US, and review medications that are currently under investigation for PrEP.

\section{Methodology}

The authors used the following search terms to search MEDLINE database to identify recently published review articles and clinical trials about upcoming treatment strategies for HIV PrEP: "HIV pre-exposure prophylaxis, 'HIV pre-exposure prophylaxis regimens', HIV preexposure prophylaxis ongoing clinical trials". Ongoing trials were identified using the ClinicalTrials.gov website, which was searched with the following search terms: "HIV pre-exposure prophylaxis". The search was limited to English-language articles as well as those published between 2015 and 2020, and to adults between 18 and 64 years old. No other search limits were applied.

Relevant articles were defined as those involving HIV regimens and strategies that are used for prophylactic purposes. Excluded studied were those that focused on pediatric patients or those that evaluated regimens used for treatment. We also excluded studies that evaluated the currently established pre-exposure prophylaxis regiments. Studies addressing social, administrative, cultural, or financial aspects of pre-exposure prophylaxis, or those that evaluated non-drug prophylactic measures, were excluded as well. For a more complete perspective, studies involving male and female populations, as well as pregnant patients were included. Conference abstracts were included as well. The MEDLINE literature search using the term "HIV pre-exposure prophylaxis" yielded 381 articles, all of which described either the established regimens, non-drug measures, or social/cultural patient factors related to pre-exposure prophylaxis. The search narrowed to search term "HIV pre-exposure prophylaxis regimens" yielded 5 articles, of which one was deemed relevant to this review. The ClinicalTrials.gov search yielded 10 articles for the search term "HIV pre-exposure prophylaxis" with the applied filters for recruiting, active not recruiting, and complete studies that are interventional, Phase III, and for the adult population (18 to 64 years old).

Additional sources of information and references were identified through the review of cited references. Article selection was based on mutual agreement for inclusion.

\section{Strategies}

Multiple layers of barriers exist resulting in slow uptake of PrEP with tenofovir/FTC. These barriers include providerlevel, patient-level, and health-systems-related or structural barriers. Provider-level barriers include lack of training in PrEP prescribing guidelines, identifying high-risk patients, how to monitor for efficacy and toxicity after patients start taking the antiretrovirals (ART), and insurance coverage. Many are also unclear as to whether primary care physicians or infectious disease physicians should prescribe PrEP to patients. Infectious disease providers are trained to deliver healthcare to patients with HIV infection and are well equipped to prescribe PrEP; however, their practice is limited to patients with established HIV infection. Primary care providers regularly care for patients without HIV infection but may lack the training necessary to prescribe PrEP. This "purview paradox" is a significant obstacle standing in the way between patients and the medications they need. Patient-level barriers include geographic location and inability to access PrEP providers, conspiracy beliefs, stigma, being uninsured or underinsured, immigration status, and competing medical or behavioral priorities such as existing medical conditions or substance abuse. Barriers in health-systems include inflexible appointment times that do 
not accommodate for work schedules, time constraints during appointments, and insufficient number of PrEP providers. $^{9-13}$ These barriers need to be overcome so persons at high risk of acquiring HIV infection can access PrEP for as long as they need it.

One of the ways to increase access to PrEP is to allow community pharmacies to open PrEP clinics. Pharmacists working in the community are in the unique position to screen high-risk patients, offer PrEP counseling, prescribe and dispense tenofovir/FTC with a collaborative drug therapy agreement (CDTA) with a physician. CDTA is an agreement between a physician and pharmacist that allows the pharmacist to initiate, modify, or discontinue drug therapy under the guidance of a protocol for a patient without the patient needing to see the physician. ${ }^{14}$ It is easier to access a pharmacist than it is to access a physician. A study conducted by Tung and colleagues saw that a pharmacistrun PrEP clinic was logistically feasible, financially viable, and had high patient retention rates (75\%) after one year of care. There were 251 persons evaluated for PrEP and 245 of them initiated PrEP. Most (96\%) did not pay a co-pay for their PrEP regimen. ${ }^{15}$ Long-term data from the same study showed that $74 \%$ of individuals were able to start their PrEP regimen on the same day as their initial appointment. Information from medication refill dates showed that $90 \%$ of patients had a mean proportion of days covered greater than $80 \%$. There were zero HIV seroconversions. ${ }^{16}$ Allowing pharmacists to open PrEP clinics through CDTAs with physicians will remove barriers for patients interested in PrEP by increasing the number of locations that are available to them. Seeking PrEP services from a pharmacist in a community pharmacy setting may also reduce a person's anxiety, because pharmacies are not directly associated with a single health condition or disease and therefore are free of PrEP or HIV stigma. ${ }^{17}$ In late 2019, California Governor Gavin Newson signed new legislation giving pharmacists the authority to dispense 30 to 60-day supply of PrEP without a prescription or a CDTA with a physician. Pharmacists will be required to complete a training program before being allowed to dispense antiretrovirals for this indication. California is the first state to implement this change in the United States. ${ }^{18}$ A study conducted in Mississippi piloted a novel method for same-day PrEP administration. They allowed pharmacists to screen people for PrEP and assess for contraindications. If a person was found to not have any contraindications to PrEP, a prescription for antiretrovirals was written without checking baseline labs. In addition, the person was given an appointment within 6 weeks to see a clinician for further assessment and labs. Most (83\%) patients received a sameday prescription for PrEP and 97\% received within 5 days. Of those who received a prescription, 77\% filled the prescription and $43 \%$ of them attended their first appointment within 6 weeks. ${ }^{19}$ Similar pharmacist-led PrEP initiatives with positive results can be seen in other trials. ${ }^{20-22}$ While expanding the role of a pharmacist does not remove all barriers to PrEP, it certainly can ease access.

Persons living in rural areas are challenged with a lack of providers close to their area of residence. Commute times and lack of transportation can pose substantial difficulties in accessing and continuing PrEP for those at high risk of acquiring HIV infection. In one research study, epidemiologists reported 1 in 8 (108,758/844,574; 13\%) PrEP-eligible MSM lived at least 30 minutes away from the nearest PrEP provider. $^{23}$ This problem can be mitigated with the use of telemedicine technologies. In a study done by Refugio and colleagues, 25 HIV-negative young men who have sex with men (YMSM) of color received PrEP services through telemedicine. At least $75 \%$ of them agreed that receiving PrEP through telemedicine technologies was fast, convenient, easy to use, and confidential. Less than $15 \%$ of the study population felt stigmatized for using PrEP. There were no HIV seroconversions during the study. ${ }^{24}$ In another study in the state of Iowa, pharmacists employed telemedicine to conduct patient interviews, order laboratory studies, and mail PrEP medications to patients. Study results showed that $91 \%$ of video visits resulted in PrEP initiation. Retention rate at 6 months was $61 \%$ and $96 \%$ of patients completed laboratory monitoring. There were 37 cases of sexually transmitted infections (STIs) that were diagnosed. ${ }^{21}$ Another study comparing retention rates among persons receiving PrEP services via telehealth vs standard in-person visits did not have as favorable results. There was no significant difference in PrEP prescription rates, first month follow-up visit, or medication adherence rate at 1 month. There were significantly less number of patients who attended their 3-month follow-up visit in the telemedicine arm compared to the standard visit arm $(40 \%$ vs $87 \% ; \mathrm{p}=0.05){ }^{25}$ Although telemedicine eases access to PrEP services, it lacks the personalization of in-person visits. This may not be important to some patients but for others, it can be the difference between staying in care or being lost to follow-up. Offering both in-person and telehealth to visits to patients when discussing PrEP might give patients more flexibility to choose a method tailored to their needs. 
The use of short message service (SMS), online web resources, and mobile apps designed to increase PrEP awareness, education, access, and adherence may also be a valuable tool to engage people at high risk for HIV transmission. Investigators compared rates of retention and PrEP adherence among persons using an online platform called PrEPmate plus standard care to those only receiving standard care. PrEPmate includes an interactive online platform where educational content is shared with consumers and SMS. Daily and weekly SMS are sent to promote adherence, answer questions, and confirm appointments. There was a statistically significant difference in adherence (PrEPmate 72\%, standard 57\%, $\mathrm{p}=0.03$ ), defined as tenofovir concentration $\geq 700 \mathrm{fmol} / \mathrm{punch}$, and retention rates (PrEPmate 86\%, standard 71\%, $\mathrm{p}=0.01$ ) among participants who used PrEPmate compared to standard of care. ${ }^{26}$ Another study investigated the use of a mobile app designed to provide various services to MSM. The app is comprised of self-assessment tools, screening questionnaire for PrEP, HIV prevention recommendations, list of PrEP providers by location, and the ability to order condoms and at-home HIV testing kits. The authors found that in a 4-month period, the app was used an average of 17.7 minutes. More than half of the participants used the app to order condoms (77/121, $63.6 \%)$ and testing kits $(64 / 121,52.8 \%)$ and $9 \%(8 / 86)$ of PrEP-eligible participants started PrEP. ${ }^{27}$ While the percentage of MSM who started PrEP does not seem significant, it is still eight more individuals on PrEP than there were prior to the use of the app. None of these interventions alone will dissolve all barriers or convince all persons that need it to start PrEP. Increasing PrEP uptake can be done by offering candidates a combination and/or a variety of interventions and choices personalized to meet their specific needs.

Patient- and provider-level PrEP stigma is an important barrier to address in order to combat poor PrEP uptake. Patients often times feel uncomfortable disclosing their sexual history to those closest to them or their healthcare providers for fear of being judged or discriminated against. PrEP users can be misunderstood to have HIV infection as medications used to treat and prevent HIV are the same. In addition, PrEP users can be labeled as promiscuous resulting in rejection by partners or loved ones. ${ }^{28-30}$ Language used in promotional materials, educational pamphlets, and multimedia outlets can perpetuate the implicit and explicit biases readers have against PrEP and PrEP users. Some of these biases are that a patient taking PrEP leads a "highrisk" lifestyle and has unconventional sexual practices when the fact is, taking PrEP as prescribed reducing risk of HIV transmission and promotes accountability for one's own health and the health of the partner. ${ }^{31}$ Words and terms such a "promiscuous", "unprotected sex", "infected" and "medication noncompliance" can be alienating and judgmental. ${ }^{32}$ Instead of focusing on the negative connotations associated with PrEP and its use, all parties involved in the PrEP continuum should discuss its positive implications such as taking responsibility for the health of oneself and others through self-advocacy and empowerment. A meta-analysis on health message framing found that gain-framed messages about prevention behaviors were more likely to be successful in encouraging patients to make positive changes than loss-framed messages. ${ }^{33}$ Gainframed messaging emphasizes the benefits of starting a healthy behavior or taking a medication whereas a lossframed messages highlight what the patient will lose if they fail to engage in said behavior or take a medication. For example, a gain-framed message about PrEP could be "Taking once-daily tenofovir/FTC will reduce your risk of acquiring HIV infection." Conversely, a loss-framed message will state the same message but in a negative context: "Not taking once-daily tenofovir/FTC will increase your risk of acquiring HIV infection." Gain-framed messages will also reduce the stigma around taking PrEP medications and thereby weaken one more barrier for patients.

Healthcare providers can unwittingly perpetuate stigma as well. There is fear within the healthcare provider community that PrEP use will be a gateway for riskier behavior. ${ }^{31,34}$ Multiple analyses have shown that risk of HIV transmission is significantly lowered when PrEP is taken as prescribed. ${ }^{35-37}$ Withholding PrEP from individuals that can benefit from it would be unethical and may increase HIV transmission rates. Educating the medical community, especially primary care providers who are at the forefront of PrEP implementation, can catalyze the scalability of PrEP.

On a policy level, there are still 14 states in the US that have not expanded Medicaid which was a service provided by the Affordable Care Act (ACA) that passed into law in 2010. A supreme court ruling in 2012 gave state governance the option to expand Medicaid coverage or leave it as is. People with low-income that live in one of these 14 states have difficulty paying for PrEP services and medications. ${ }^{38}$ Medicaid expansion in all 50 states would remove the financial burden of starting PrEP in people with low-income.

The states of New York, Massachusetts, and Washington in the United States have adopted PrEP patient assistance programs for those that are uninsured or underinsured. 
Prescribers registered with the program will be reimbursed by the state for services such as HIV testing, counseling, STD testing, and supportive care services. PrEP medication is not covered through this state program but eligible patients can receive tenofovir/FTC for free through the manufacturer's (Gilead) patient assistance program. An individual is considered eligible for Gilead Advancing Access Medication Assistance Program if he/she is uninsured and the household income is 500\% Federal Poverty Level (FPL) regardless of immigration status. ${ }^{39}$ These state and private programs offset the cost of PrEP care for patients. ${ }^{14,40}$ The availability of such programs is invaluable to patients with financial barriers and can significantly impact PrEP uptake. In fact, the 3 states with patient assistance programs are among the top 5 states with the highest PrEP uptake rates in the US. ${ }^{41}$ Table 1 contains a summary of the strategies discussed in this article.

\section{Target Populations}

Target population that can benefit from PrEP includes individuals at high-risk of acquiring HIV. Men who have sex with men (MSM) account for the largest proportion among other subpopulation, leading most prevention efforts to focus on identifying HIV risk factors among MSM. Within the MSM population, black and Hispanic MSM are disproportionately affected by the slow uptake of PrEP. ${ }^{42,43}$ A study in Atlanta, USA surveyed 436 black MSM about PrEP awareness. Black MSM unaware of PrEP had lower rates of HIV testing knowledge, less HIV testing rates, and higher rates of transactional sex. This study demonstrated that those that were at highest risk for HIV infection had lower rates of PrEP awareness and HIV testing. ${ }^{44}$

One study developed a multivariable prediction model developed using the medical records from a Sexually Transmitted Disease (STD) clinic estimated a higher likelihood of acquiring HIV among the MSM with a diagnosis of STD and substance use. The model also constructed a risk score of HIV acquisition and suggested the clinicians use it to identify candidates for intensive prevention activities such as PrEP. The clinicians can calculate patient's risk score (ranged 0 to 19) based on patient's answers to four questions, find out patient's estimated 4-year HIV risk using the chart provided, and develop a follow-up plan such as testing recommendation or prevention intervention. ${ }^{45}$ Another risk score to screen high-risk MSM was developed using a clinical trial data on MSM who had not used injection drugs. ${ }^{46}$
In addition, heterosexual men and women who practice risky sexual behaviors are candidates of PrEP. For example, individuals having unprotected sex or having multiple sex partners are more likely to acquire HIV. ${ }^{47,48}$ In addition, likelihood of being exposed to a HIV-infected partner is greater in the communities that are known to have a high HIV prevalence such as non-Hispanic black community or low-income population. ${ }^{49-51}$ Moreover, commercial sex workers and prison inmates are known to be high-risk heterosexual subgroups that would need intensive prevention activities. ${ }^{52}$ Therefore, the efforts to increase PrEP uptake could be prioritized to these communities to reduce a risk of HIV exposure.

\section{PrEP Medication Regimens Under Investigation}

The National Institute of Allergy and Infectious Diseases (NIAID) is evaluating the efficacy of long-acting cabotegravir compared to TDF/FTC in HIV-uninfected women who are at risk for HIV. This is a randomized parallel assignment study with two multi-step treatment arms: oral cabotegravir, oral TDF/FTC, and long-acting IM cabotegravir. The primary outcome measures are the number of documented HOV infections as well as number of adverse events. The study is currently recruiting eligible patients throughout several African locations, has an estimated enrollment of 3200 participants, and is expected to be completed in May $2022 .{ }^{53}$ The NIAID is currently recruiting participants for a study evaluating the safety and efficacy of cabotegravir for PrEP in HIV-uninfected cisgender men and transgender women who have sex with men. Study participants will be randomized into 1 of 2 arms: (1) daily oral CAB tablets and daily oral TDF/FTC placebo tablets for 5 weeks (step 1) IM injection of $\mathrm{CAB}$ at 2 time points 4 weeks apart and every 8 weeks thereafter and daily oral TDF/FTC placebo tablets to week 153 (step 2); (2) daily oral TDF/FTC tablets and daily oral $\mathrm{CAB}$ placebo tablets for 5 weeks (step 1) daily oral TDF/ FTC tablets and an IM injection of placebo at 2 time points 4 weeks apartment and every 8 weeks thereafter to week 153 (step 2). Step 3 involves all participants in both arms receiving daily oral TDF/FTC tablets starting week 153 and continuing for 48 weeks. Primary outcomes measures are number of documented incident HIV infections and number of Grade 2 or higher clinical and laboratory adverse events. The estimated study completion date is March 2022. ${ }^{54}$ 
Table I Strategies to Increase PrEP Uptake $9-4$ I

\begin{tabular}{|c|c|}
\hline Barrier & Strategies to Implement \\
\hline "Purview paradox" & $\begin{array}{l}\text { - Educating primary care providers (PCP) about their role in preventing HIV transmission and PrEP } \\
\text { prescribing } \\
\text { - Empowering PCPs to discuss PrEP with their patients by providing them with the necessary tools and } \\
\text { resources such as allocating appointment time slots for PrEP candidates and furnishing the exam rooms } \\
\text { with educational pamphlets } \\
\text { - Expanding the role of infectious disease providers to provide services to PrEP candidates }\end{array}$ \\
\hline $\begin{array}{l}\text { Transportation barriers and PrEP } \\
\text { provider deserts }\end{array}$ & $\begin{array}{l}\text { - Use telemedicine technologies to interview patients, order laboratory monitoring, and prescribe PrEP } \\
\text { - Change legislature to allow pharmacists to test for HIV and prescribe PrEP regimens; arrange CDTAs } \\
\text { between pharmacists and physicians so pharmacists can operate PrEP clinics, counsel patients, order } \\
\text { laboratory monitoring, and initiate/modify/discontinue PrEP } \\
\text { - Utilize apps, websites, and SMS to interact with patients in a virtual platform and keep them informed } \\
\text { about their appointments, medications, and general information about PrEP }\end{array}$ \\
\hline Patient- and provider-level stigma & $\begin{array}{l}\text { - Gain-framed health messaging and reduce stigma and increase patient buy-in } \\
\text { - Educate healthcare providers of the benefits of PrEP in reducing HIV transmission } \\
\text { - Create educational material with positive messaging and remove verbiage that further stigmatize the use } \\
\text { of PrEP such as "promiscuous", "high-risk", "infected", "unprotected sex", "medication noncompliance". }\end{array}$ \\
\hline Financial burden of PrEP & $\begin{array}{l}\text { - Increasing Medicaid expansion to all states in the US } \\
\text { - Creating private and state level patient assistance programs for PrEP in order to offset cost to providers } \\
\text { and patients }\end{array}$ \\
\hline
\end{tabular}

Gilead Sciences is currently conducting a Phase III, randomized, double-blind study to evaluate the efficacy and safety and emtricitabine and tenofovir alafenamide (F/TAF) fixeddose combination once-daily regimen, for pre-exposure prophylaxis in men and transgender women who have sex with men and are at risk of HIV-1 Infection. This study is ongoing with anticipated completion date in September 2021. ${ }^{55}$

The International Partnership for Microbicides (IPM) guided two studies that evaluated the efficacy of a dapivirine vaginal ring. The first trial, titled "The Ring Study", was completed in 2016 and showed a 31\% decreased incidence of HIV-1 infection in HIV negative, healthy women, and was not associated with any safety concerns. ${ }^{56}$ These findings were also confirmed in a separate NIAID study, ASPIRE, as well as National Institute of Health (NIH)supported HOPE study. ${ }^{57,58}$ The second IPM-led study, the DREAM trial, was an extension trial that took place at six former Ring Study locations. ${ }^{59}$ It was completed in January 2019, and confirmed the results of the Ring Study with a $63 \%$ HIV risk reduction in women. The ring device is currently under European regulatory agency review, with plans to seek FDA approval in the US. ${ }^{60}$

NIAID is currently recruiting participants for another extension study that will investigate the safety of and adherence to dapivirine vaginal ring in adolescent and young female population. This is a Phase IIa randomized, openlabel, crossover study with the following outcome measures: frequency of adverse events, detectable drug levels in blood, and percentage of participants reporting acceptability and preference for dapivirine vaginal ring. The study is expected to be completed in November 2021. ${ }^{61}$

The HIV Vaccine Trials Network and the HIV Prevention Trials Network are also currently investigating a new preventive strategy that is related to what has been done in HIV vaccine research. ${ }^{62}$ The Antibody Mediated Prevention Study will investigate the direct intravenous infusion of VRC01 antibody, which was previously studied and as a treatment option in the Red Cross Research Center in Bangkok, Thailand. The trial showed that the antibody was well tolerated; however, it did not significantly increase the number of participants with viral suppression, prompting further research in this field. ${ }^{63}$

Another strategy investigated as PrEP is a reservoirstyle implant for sustained release of TAF as a novel formulation for antiretroviral drug delivery and prophylaxis. ${ }^{64}$ Pharmacokinetic studies so far have shown sustained plasma TAF concentrations, as well as in-vivo TAF release rate of active implants that correlated well with the in-vitro TAF release from similar devices. This makes the TAF device suitable for continued development as a longacting subcutaneous implant for HIV PrEP. ${ }^{65}$ 
Table 2 Summary of PrEP Regimens/Strategies Under Investigation

\begin{tabular}{|c|c|c|c|c|c|c|}
\hline $\begin{array}{l}\text { Authors/ } \\
\text { Sponsor }\end{array}$ & Title & Study Design & Studied Regimen & Study Objective & $\begin{array}{l}\text { Status of } \\
\text { the Study }\end{array}$ & $\begin{array}{l}\text { Results } \\
\text { (Where } \\
\text { Available) }\end{array}$ \\
\hline $\begin{array}{l}\text { Gilead } \\
\text { Sciences }{ }^{55}\end{array}$ & $\begin{array}{l}\text { A Phase III, Randomized, } \\
\text { Double-blind Study to } \\
\text { Evaluate the Safety and } \\
\text { Efficacy of Emtricitabine } \\
\text { and Tenofovir Alafenamide } \\
\text { (F/TAF) Fixed-Dose } \\
\text { Combination Once Daily } \\
\text { for Pre-Exposure } \\
\text { Prophylaxis in Men and } \\
\text { Transgender Women Who } \\
\text { Have Sex With Men and } \\
\text { Are At Risk of HIV-I } \\
\text { Infection }\end{array}$ & $\begin{array}{l}\text { Randomized, parallel } \\
\text { assignment, double } \\
\text { blind, placebo controlled } \\
\text { clinical trial with } 5400 \\
\text { participants }\end{array}$ & $\begin{array}{l}\text { Daily emtricitabine/ } \\
\text { tenofovir alafenamide (F/ } \\
\text { TAF) or emtricitabine/ } \\
\text { tenofovir DF (F/TDF) }\end{array}$ & $\begin{array}{l}\text { To assess the rates of HIV-I } \\
\text { infection in MSM and } \\
\text { transgender women who } \\
\text { have sex with men }\end{array}$ & $\begin{array}{l}\text { Phase III, } \\
\text { ongoing }\end{array}$ & N/A \\
\hline $\begin{array}{l}\text { The National } \\
\text { Institute of } \\
\text { Allergy and } \\
\text { Infectious } \\
\text { Diseases } \\
(\text { NIAID) })^{53}\end{array}$ & $\begin{array}{l}\text { Evaluating the Safety and } \\
\text { Efficacy of Long-Acting } \\
\text { Injectable Cabotegravir } \\
\text { Compared to Daily Oral } \\
\text { TDF/FTC for Pre- } \\
\text { Exposure Prophylaxis in } \\
\text { HIV-Uninfected Women }\end{array}$ & $\begin{array}{l}\text { Randomized, quadruple } \\
\text { blinded, parallel } \\
\text { assignment clinical trial } \\
\text { with } 3200 \text { participants }\end{array}$ & $\begin{array}{l}\text { Long-acting injectable } \\
\text { integrase inhibitor } \\
\text { cabotegravir (CAB LA) vs } \\
\text { oral daily tenofovir } \\
\text { disoproxil fumarate/ } \\
\text { emtricitabine (TDF/FTC) }\end{array}$ & $\begin{array}{l}\text { Evaluate the safety and } \\
\text { efficacy of the long-acting } \\
\text { injectable agent } \\
\text { cabotegravir (CAB LA) } \\
\text { compared to daily oral } \\
\text { tenofovir disoproxil } \\
\text { fumarate/emtricitabine } \\
\text { (TDF/FTC) for pre- } \\
\text { exposure prophylaxis } \\
\text { (PrEP) in HIV-uninfected } \\
\text { women }\end{array}$ & $\begin{array}{l}\text { Phase III, } \\
\text { Recruiting }\end{array}$ & N/A \\
\hline $\begin{array}{l}\text { The } \\
\text { International } \\
\text { Partnership } \\
\text { for } \\
\text { Microbicides } \\
(\text { IPM })^{56}\end{array}$ & $\begin{array}{l}\text { Open-label Study of IPM's } \\
\text { Dapivirine Vaginal Ring } \\
\text { Show Increased Use and } \\
\text { Suggest Lower Infection } \\
\text { Rates Compared to Earlier } \\
\text { Phase III Study }\end{array}$ & $\begin{array}{l}\text { Open-label study } \\
\text { conducted in South } \\
\text { Africa and Uganda that } \\
\text { followed } 941 \text { women } \\
\text { ages } 20-50 \text { for } 12 \\
\text { months. The }\end{array}$ & Dapivirine vaginal ring & $\begin{array}{l}\text { To collect additional safety } \\
\text { data and information on } \\
\text { how women who } \\
\text { participated in an earlier } \\
\text { Phase III trial, used the ring }\end{array}$ & $\begin{array}{l}\text { Completed; } \\
\text { under } \\
\text { review by } \\
\text { European } \\
\text { Medicines } \\
\text { Agency }\end{array}$ & $\begin{array}{l}\text { Increased } \\
\text { use of the } \\
\text { ring and } \\
63 \% \\
\text { reduction } \\
\text { in HIV risk }\end{array}$ \\
\hline $\begin{array}{l}\text { The National } \\
\text { Institute of } \\
\text { Allergy and } \\
\text { Infectious } \\
\text { Diseases } \\
(\text { NIAID) })^{61}\end{array}$ & $\begin{array}{l}\text { Evaluating the Safety of and } \\
\text { Adherence to a Vaginal } \\
\text { Matrix Ring Containing } \\
\text { Dapivirine and Oral } \\
\text { Emtricitabine/Tenofovir } \\
\text { Disoproxil Fumarate in an } \\
\text { Adolescent and Young } \\
\text { Adult Female Population. }\end{array}$ & $\begin{array}{l}\text { Randomized, open-label, } \\
\text { crossover trial with } 300 \\
\text { female patients ages } \\
|6-2| \text { years }\end{array}$ & $\begin{array}{l}\text { Dapivirine vaginal ring vs } \\
\text { FTC/TDF }\end{array}$ & $\begin{array}{l}\text { To evaluate the safety of } \\
\text { and adherence to a vaginal } \\
\text { matrix ring (VR) containing } \\
\text { dapivirine and oral FTC/ } \\
\text { TDF }\end{array}$ & Phase lla & N/A \\
\hline $\begin{array}{l}\text { The HIV } \\
\text { Vaccine Trials } \\
\text { Network and } \\
\text { the HIV } \\
\text { Prevention } \\
\text { Trials } \\
\text { Network }\end{array}$ & $\begin{array}{l}\text { The Antibody-Mediated } \\
\text { Study }\end{array}$ & N/A & $\begin{array}{l}\text { Direct intravenous infusion } \\
\text { of VRCOI antibody }\end{array}$ & $\begin{array}{l}\text { To study the response to } \\
\text { a direct infusion of VRCOI } \\
\text { antibody }\end{array}$ & $\begin{array}{l}\text { Enrollment } \\
\text { completed }\end{array}$ & N/A \\
\hline
\end{tabular}

(Continued) 
Table 2 (Continued).

\begin{tabular}{|c|c|c|c|c|c|c|}
\hline $\begin{array}{l}\text { Authors/ } \\
\text { Sponsor }\end{array}$ & Title & Study Design & Studied Regimen & Study Objective & $\begin{array}{l}\text { Status of } \\
\text { the Study }\end{array}$ & $\begin{array}{l}\text { Results } \\
\text { (Where } \\
\text { Available) }\end{array}$ \\
\hline $\begin{array}{l}\text { University of } \\
\text { KwaZulu }\end{array}$ & $\begin{array}{l}\text { Immediate or Deferred } \\
\text { Pre-exposure Prophylaxis } \\
\text { for HIV Prevention: Safe } \\
\text { Options for Pregnant and } \\
\text { Lactating Women (PrEP) }\end{array}$ & $\begin{array}{l}\text { An open-label } \\
\text { randomized control } \\
\text { study with estimated } \\
\text { enrollment of } 842 \\
\text { pregnant women } \\
\text { considered at high risk } \\
\text { for HIV infection }\end{array}$ & $\begin{array}{l}\text { Standard HIV prevention } \\
\text { strategy plus once daily } \\
\text { TDF/FTC initiated in } \\
\text { pregnancy and continued } \\
\text { until breastfeeding } \\
\text { cessation or } 18 \text { months } \\
\text { after delivery, whichever is } \\
\text { earliest vs standard HIV } \\
\text { prevention strategy } \\
\text { throughout pregnancy until } \\
\text { breastfeeding cessation }\end{array}$ & $\begin{array}{l}\text { To explore the safety of } \\
\text { TDF/FTC when used as } \\
\text { PrEP during pregnancy and } \\
\text { lactation }\end{array}$ & $\begin{array}{l}\text { Phase II and } \\
\text { III, } \\
\text { recruiting }\end{array}$ & N/A \\
\hline $\begin{array}{l}\text { National } \\
\text { Institute of } \\
\text { Allergy and } \\
\text { Infectious } \\
\text { Diseases } \\
\text { (NIAID) } \\
\text { And ViiV } \\
\text { Healthcare } \\
\text { and Gilead } \\
\text { Sciences }\end{array}$ & $\begin{array}{l}\text { Safety and Efficacy Study of } \\
\text { Injectable Cabotegravir } \\
\text { Compared to Daily Oral } \\
\text { Tenofovir Disoproxil } \\
\text { Fumarate/Emtricitabine } \\
\text { (TDF/FTC), For Pre- } \\
\text { Exposure Prophylaxis in } \\
\text { HIV-Uninfected Cisgender } \\
\text { Men and Transgender } \\
\text { Women Who Have Sex } \\
\text { With Men }\end{array}$ & $\begin{array}{l}\text { Randomized, double- } \\
\text { blind, parallel with } \\
\text { estimated enrollment of } \\
5000 \text { HIV-uninfected } \\
\text { cisgender men and } \\
\text { transgender women } \\
\text { who have sex with men }\end{array}$ & $\begin{array}{l}2 \text { arms: (arm I) daily oral } \\
\text { CAB tablets and daily oral } \\
\text { TDF/FTC placebo tablets } \\
\text { for } 5 \text { weeks (step I) IM } \\
\text { injection of CAB at } 2 \text { time } \\
\text { points } 4 \text { weeks apart and } \\
\text { every } 8 \text { weeks thereafter } \\
\text { and daily oral TDF/FTC } \\
\text { placebo tablets to week } \\
\text { 153 (step 2); (arm 2) daily } \\
\text { oral TDF/FTC tablets and } \\
\text { daily oral CAB placebo } \\
\text { tablets for } 5 \text { weeks (step I) } \\
\text { daily oral TDF/FTC tablets } \\
\text { and an IM injection of } \\
\text { placebo at } 2 \text { time points } 4 \\
\text { weeks apartment and every } \\
8 \text { weeks thereafter to week } \\
\text { I53 (step 2). Step } 3 \\
\text { involves all participants in } \\
\text { both arms receiving daily } \\
\text { oral TDF/FTC tablets } \\
\text { starting week I53 and } \\
\text { continuing for } 48 \text { weeks. }\end{array}$ & $\begin{array}{l}\text { To evaluate the safety and } \\
\text { efficacy of cabotegravir for } \\
\text { PrEP in HIV-uninfected } \\
\text { cisgender men and } \\
\text { transgender women who } \\
\text { have sex with men }\end{array}$ & $\begin{array}{l}\text { Phase IIb/III, } \\
\text { recruiting }\end{array}$ & N/A \\
\hline $\begin{array}{l}\text { Kirby } \\
\text { Institute }\end{array}$ & $\begin{array}{l}\text { Expanded PrEP } \\
\text { Implementation in } \\
\text { Communities in NSW } \\
\text { (EPIC-NSW) }\end{array}$ & $\begin{array}{l}\text { Single, open-label arm } \\
\text { with } 9733 \text { participants } \\
\text { enrolled (adults at high } \\
\text { risk of HIV, mostly gay } \\
\text { and bisexual men) }\end{array}$ & One pill daily TDF/FTC & $\begin{array}{l}\text { To assess the incidence of } \\
\text { HIV among PrEP study } \\
\text { participants and measure } \\
\text { the population-level impact } \\
\text { of the rapid roll-out of PrEP } \\
\text { on HIV diagnoses among } \\
\text { gay and bisexual men in } \\
\text { NSW over a two-year } \\
\text { period. }\end{array}$ & $\begin{array}{l}\text { Phase III, } \\
\text { active, not } \\
\text { recruiting }\end{array}$ & N/A \\
\hline
\end{tabular}

The University of KwaZulu is conducting an openlabel, randomized control study on the safety of TDF/ FTC in PrEP during pregnancy and lactation. Pregnant women at risk for HIV will be randomized to one of two arms in which participants are either initiated on PrEP in pregnancy and continue using TDF/FTC throughout breastfeeding or PrEP is deferred until breastfeeding cessation. The two arms are (1) standard HIV prevention strategy plus once-daily TDF/FTC initiated in pregnancy and continued until breastfeeding cessation or 18 months after delivery, whichever is earliest and (2) standard HIV prevention strategy throughout pregnancy until 
breastfeeding cessation. The primary outcomes measures are pregnancy outcome-preterm deliveries, bone mineral density in mother and infant, and pregnancy outcome-low birth weight. Other outcomes include incident HIV infections and adherence to PrEP. This study is estimated to be completed in May 2022. ${ }^{66}$ A study by the Kirby Institute is evaluating the incidence of HIV among PrEP study participants and population-level impact of a rapid rollout of PrEP on HIV diagnoses amongst gay and bisexual men over a 2-year period. This is a single open-label arm study in which all participants will receive daily oral TDF/ FTC. The primary outcome measures are incidence of HIV infection per 100-person years among study participants and number of HIV diagnoses among gay and bisexual men notified to the New South Wales Ministry of Health. The study is estimated to be completed in October 2020. ${ }^{67}$ Table 2 contains a summary of drugs under investigation.

\section{Conclusion}

The uptake of PrEP among high-risk patient groups is critical in fighting the HIV epidemic. Identifying target populations and utilizing different strategies to combat barriers is needed to increase access to PrEP services. Research in alternative PrEP methods is ongoing.

\section{Disclosure}

The authors report no conflicts of interest in this work.

\section{References}

1. Centers for Disease Control and Prevention. Preexposure prophylaxis for the prevention of HIV infection in the United States - 2017 update; Available from: 2018. https://www.cdc.gov/hiv/pdf/risk/prep/cdc-hivprep-guidelines-2017.pdf. Accessed December 9, 2019.

2. US Food and Drug Administration. FDA approves second drug to prevent HIV infection as part of ongoing efforts to end the HIV epidemic; 2019. Available from: https://www.fda.gov/news-events/press-announcements /fda-approves-second-drug-prevent-hiv-infection-part-ongoing-effortsend-hiv-epidemic. Accessed December 10, 2019.

3. European AIDS Clinical Society. Guidelines - version 10.0; 2019. Available from: https://www.eacsociety.org/files/2019_guidelines-10. 0_final.pdf. Accessed December 12, 2019.

4. Centers for Disease Control and Prevention. PrEP. 2019. https://www. cdc.gov/hiv/basics/prep.html. Accessed December 10, 2019.

5. AIDSvu. Mapping PrEP: first ever data on PrEP users across the US. Emory university rollins school of public health; 2020. Available from: https://aidsvu.org/prep/. Accessed November 2, 2020.

6. World Health Organization. Pre-exposure prophylaxis; 2020. Available from: https://www.who.int/hiv/topics/prep/en/. Accessed February 11, 2020.

7. Pyra M, Haberer J, Hasen N, Reed J, Mugo N, Baeten J. Global implementation of PrEP for HIV prevention: setting expectations for impact. J Int AIDS Soc. 2019;22(8):e25370. doi:10.1002/jia2.25370
8. UNAIDS. Access to PrEP being held back; 2019. Available from: https://www.unaids.org/sites/default/files/media/images/access-toPrEP-being-held-back.png. Accessed February 11, 2020.

9. Pinto R, Berringer K, Melendez R, Mmeje O. Improving PrEP implementation through multilevel interventions: a synthesis of the literature. AIDS Behav. 2018;22(11):3681-3691. doi:10.1007/s10461018-2184-4

10. Brooks R, Allen Jr V, Regan R, Mutchler M, Cervantes-Tadeo R, Lee S. HIV/AIDS conspiracy beliefs and intention to adopt HIV pre-exposure prophylaxis among black men who have sex with men in Los Angeles. Int J STD AIDS. 2018;29(4):375-381. doi:10.1177/ 0956462417727691

11. Page K, Martinez O, Nieves-Lugo K, et al. Promoting pre-exposure prophylaxis to prevent HIV infections among sexual and gender minority Hispanics/Latinxs. AIDS Educ Prev. 2017;29(5):389-400. doi:10.1521/aeap.2017.29.5.389

12. Martinez O, Wu E, Levine E, et al. Integration of social, cultural, and biomedical strategies into an existing couple-based behavioral HIV/ STI prevention intervention: voices of Latino male couples. PLoS One. 2016;11(3):e0152361. doi:10.1371/journal.pone.0152361

13. Palazzolo S, Yamanis T, De Jesus M, Maguire-Marshall M, Barker S. Documentation status as a contextual determinant of HIV risk among young transgender Latinas. LGBT Health. 2016;3(2):132-138. doi:10.1089/lgbt.2015.0133

14. Sullivan P, Mena L, Elopre L, Siegler A. Implementation strategies to increase PrEP uptake in the South. Curr HIV/AIDS Rep. 2019;16 (4):259-269. doi:10.1007/s11904-019-00447-4

15. Tung E, Thomas A, Eichner A, Shalit P Feasibility of a pharmacist-run HIV PrEP clinic in a community pharmacy setting. In: Conference on Retroviruses and Opportunistic Infections (CROI). Accessed July 10, 2020; Seattle, WA. 2017. http://www.croiconference.org/sessions/feasi bility-pharmacist-run-hiv-prep-clinic-community-pharmacy-setting.

16. Tung E, Thomas A, Eichner A, Shalit P. Implementation of a community pharmacy-based pre-exposure prophylaxis service: a novel model for pre-exposure prophylaxis care. Sex Health. 2018;15(6):556-561. doi:10.1071/SH18084

17. Myers J, Farhat D, Guzman A, Arya V. Pharmacists in HIV prevention: an untapped potential. Am J Public Health. 2019;109 (6):859-861. doi:10.2105/AJPH.2019.305057

18. Hamm N. California bill increases pharmacist powers: new bill allows pharmacists to initiate HIV medication. Drug Topics. 2019;163(11):36.

19. Khosropour C, Backus K, Means A, et al. A pharmacist-led, same-day, HIV pre-exposure prophylaxis initiation program to increase PrEP uptake and decrease time to PrEP initiation. AIDS Patient Care STDS. 2020;34(1):1-6. doi:10.1089/apc.2019.0235

20. Smith B, Hester A, Cantos V, James T, Lora M. A pharmacist-led PrEP program at the epicenter of the HIV epidemic in Atlanta; our experience. Open Forum Infectious Diseases. 2019; 6(suppl 2):S461. doi:10.1093/ofid/ofz360.1143.

21. Hoth A, Shafer C, Dillon D, Mayer R, Walton G, Ohl M. Iowa TelePrEP: a public-health-partnered telehealth model for HIV pre-exposure prophylaxis (PrEP) delivery in a rural state. Sex Transm Dis. 2019;46 (8):507-512. doi:10.1097/OLQ.0000000000001017

22. Keenan R, Lewis J, Sanchez D, Anderson B, Mercier R. The Next Step in PrEP: Evaluating Outcomes of a Pharmacist-Run HIV PreExposure Prophylaxis (Prep) Clinic. ID Week; 2018.

23. Siegler A, Bratcher A, Weiss K. Geographic access to preexposure prophylaxis clinics among men who have sex with men in the United States. Am J Public Health. 2019;109(9):1216-1223. doi:10.2105/ AJPH.2019.305172

24. Refugio O, Kimble M, Silva C, Lykens J, Bannister C, Klausner J. Brief report: prEPTECH: a telehealth-based initiation program for HIV pre-exposure prophylaxis in young men of color who have sex with men. A pilot study of feasibility. J Acquir Immune Defic Syndr. 2019;80(1):40-45. doi:10.1097/QAI.0000000000001873 
25. Stekler J, McMahan V, Ballinger L, et al. HIV pre-exposure prophylaxis prescribing through telehealth. J Acquir Immune Defic Syndr. 2018;77(5):e40-e42. doi:10.1097/QAI.0000000000001621

26. Liu A, Vittinghoff E, von Felten P, et al. Randomized controlled trial of a mobile health intervention to promote retention and adherence to preexposure prophylaxis among young people at risk for human immunodeficiency virus: the EPIC study. Clin Infect Dis. 2019;68 (12):2010-2017. doi:10.1093/cid/ciy810

27. Sullivan P, Driggers R, Stekler J, et al. Usability and acceptability of a mobile comprehensive HIV prevention app for men who have sex with men: a pilot study. JMIR Mhealth Uhealth. 2017;5(3):e26. doi:10.2196/mhealth.7199

28. Biello K, Oldenburg C, Mitty J, et al. The "safe sex" conundrum: anticipated stigma from sexual partners as a barrier to PrEP use among substance using MSM engaging in transactional sex. AIDS Behav. 2017;21(1):300-306. doi:10.1007/s10461-016-1466-y

29. Golub S, Gamarel K, Surace A. Demographic differences in PrEP-related stereotypes: implications from implementation. AIDS Behav. 2017;21(5):1229-1235. doi:10.1007/s10461-015-1129-4

30. Dubov A, Galbo P, Altice F, Fraenkel L. Stigma and shame experiences by MSM who take PrEP for HIV prevention: a qualitative study. Am J Mens Health. 2018;12(6):1843-1854. doi:10.1177/ 1557988318797437

31. Golub S. PrEP stigma: implicit and explicit drivers of disparity. Curr HIV/AIDS Rep. 2018;15(2):190-197. doi:10.1007/s11904-018-0385-0

32. Lynn V, Watson C, Giwa-Onaiwu M, Ray V, Gallagner B, Wojciechowicz V. HIV \#languagematters: addressing stigma by using preferred language. Available from: https:/hiveonline.org/wpcontent/uploads/2016/01/Anti-StigmaSign-Onletter1.pdf. Accessed July 10, 2020.

33. Gallagher K, Updegraff J. Health message framing effects on attitudes, intentions, and behavior: a meta-analytic review. Ann Behav Med. 2012;43(1):101-116. doi:10.1007/s12160-011-9308-7

34. Castro D, Delabre R, Molina J. Give PrEP a chance: moving on from the "risk compensation" concept. J Int AIDS Soc. 2019;22(6):e25351. doi: $10.1002 /$ jia 2.25351

35. Volk J, Marcus J, Phengrasamy T, et al. No new HIV infections with increasing use of HIV preexposure prophylaxis in a clinical practice setting. Clin Infect Dis. 2015;61(10):1601-1603. doi:10.1093/cid/civ778

36. Jenness S, Goodreau S, Rosenberg E, et al. Impact of the centers for disease control's HIV preexposure prophylaxis guidelines for men who have sex with men in the United States. J Infect Dis. 2016;214 (12):1800-1807. doi:10.1093/infdis/jiw223

37. Anderson P, Glidden D, Liu A, et al. Emtricitabine-tenofovir concentrations and pre-exposure prophylaxis efficacy in men who have sex with men. Sci Transl Med. 2012;4(151):151ra125. doi:10.1126/ scitranslmed.3004006

38. Norris L A state-by-state guide to medicaid expansion, eligibility, enrollment and benefits; 2020. Available from: https://www.healthin surance.org/medicaid/. Accessed February 19, 2020.

39. Private PrEP medication assistance program for uninsured patients. https://www.nastad.org/prepcost-resources/prep-assistanceprograms\#: :text=WHAT IT COVERS\%3A The program,individuals $\% 2 \mathrm{C}$ regardless of immigration status.Accessed June 10, 2020.

40. PrEP patient assistance program (PrEP-AP). New York State; 2015. Available from: https://www.health.ny.gov/diseases/aids/general/ prep/prep-ap_provider.htm. Accessed February 19, 2020.

41. Sullivan P, Giler R, Mouhanna F, et al. Trends in the use of oral emtricitabine/tenofovir disoproxil fumarate for pre-exposure prophylaxis against HIV infections, United States, 2012-2017. Ann Epidemiol. 2018;28(12):833-840. doi:10.1016/j.physbeh.2017.03.040

42. Kanny D, Jeffries W, Chapin-Bardales J, et al. Racial/ethnic disparities in HIV preexposure prophylaxis among men who have sex with men - 23 urban areas, 2017; 2019. Morbidity and Mortality Weekly Report. Available from: https://www.cdc.gov/mmwr/volumes/68/wr/ mm6837a2.htm\#T1_down. Accessed January 2, 2020.
43. Rao S, Seth P, Walker T, et al. HIV testing and outcomes among Hispanics/Latinos - United States, Puerto Rico, and US Virgin Islands, 2014. Morb Mortal Wkly Rep. 2016;65(40):1099-1103. doi:10.15585/mmwr.mm6540a2

44. Eaton LA, Driffin DD, Bauermeister J, Smith H, ConwayWashington C. Minimal awareness and stalled uptake of Pre-Exposure Prophylaxis (PrEP) among at risk, HIV-negative, black men who have sex with men. AIDS Patient Care STDS. 2015;29(8):423-429. doi:10.1089/apc.2014.0303

45. Menza TW, Hughes JP, Celum CL, Golden MR. Prediction of HIV acquisition among men who have sex with men. Sex Transm Dis. 2009;36(9):547-555. doi:10.1097/OLQ.0b013e3181a9cc41

46. Smith DK, Pals SL, Herbst JH, Shinde S, Carey JW. Development of a clinical screening index predictive of incident HIV infection among men who have sex with men in the United States. $J$ Acquir Immune Defic Syndr. 2012;60(4):421-427. doi:10.1097/QAI.0b013e31825 $6 \mathrm{~b} 2 \mathrm{f} 6$

47. Pinkerton SD, Abramson PR. Effectiveness of condoms in preventing HIV transmission. Soc Sci Med. 1997;44(9):1303-1312. doi:10.1016/ S0277-9536(96)00258-4

48. Do M, Meekers D. Multiple sex partners and perceived risk of HIV infection in Zambia: attitudinal determinants and gender differences. AIDS Care. 2009;21(10):1211-1221. doi:10.1080/09540120902 730047

49. Dean H, Steele C, Satcher A. HIV/AIDS among minority races and ethnicities in the United States, 1999-2003. J Natl Med Assoc. 2005;97(7 suppl):5S-12S.

50. Caponi M, Burgess C, Leatherwood A, Molano LF. Demographic characteristics associated with the use of HIV pre-exposure prophylaxis (PrEP) in an urban, community health center. Prev Med Rep. 2019;15:100889. doi:10.1016/j.pmedr.2019.100889

51. Lalota M, Beck D, Metsch L, et al. HIV seropositivity and correlates of infection among heterosexually active adults in high-risk areas in South Florida. AIDS Behav. 2011;15(6):1259-1263. doi:10.1007/ s10461-010-9856-Z

52. Jenness S, Neaigus A, Murrill C, Wendel T, Forgione L, Hagan H. Estimated HIV incidence among high-risk heterosexuals in New York city, 2007. J Acquir Immune Defic Syndr. 2011;56(2):193-197. doi:10.1097/QAI.0b013e318202a9c4

53. The National Institute of Allergy and Infectious Diseases. Evaluating the safety and efficacy of the long-acting injectable cabotegravir compared to daily oral tenofovir disoproxil fumarate/emtricitabine (TDF/FTC) for pre-exposure prophylaxis (PrEP) in HIV-uninfected women. ClinicalTrials.gov identifier: NCT03164564. Available from: https://clinicaltrials.gov/ct2/show/NCT03164564\#contacts. Accessed February 7, 2020.

54. Safety and efficacy study of injectable cabotegravir compared to daily oral tenofovir disoproxil fumarate/emtricitabine (TDF/FTC), for pre-exposure prophylaxis in HIV-uninfected cisgender men and transgender women who have sex with men. ClinicalTrials.gov. https://clinicaltrials.gov/ct2/show/NCT02720094. Accessed February 3, 2020.

55. Gilead Sciences. A phase 3, randomized, double-blind study to evaluate the safety and efficacy of emtricitabine and tenofovir alafenamide (F/TAF) fixed-dose combination once daily for pre-exposure prophylaxis in men and transgender women who have sex with men and are at R. Clinical trials.gov identifier NCT02842086. Available from: https://clinicaltrials.gov/ct2/show/NCT02842086. Accessed March 14, 2020.

56. Nel A, Van Niekerk N, Kapiga S, et al. Safety and efficacy of a dapivirine vaginal ring for HIV prevention in women. $N$ Engl J Med. 2016;375(22):2133-2143. doi:10.1056/NEJMoa1602046

57. Baeten JM, Palanee-Phillips T, Brown ER, et al. Use of a vaginal ring containing dapivirine for HIV-1 prevention in women. $N$ Engl J Med. 2016;375(22):2121-2132. doi:10.1056/NEJMoa1506110 
58. Baeten J, Palanee-Phillips T, Mgodi N, et al. High adherence and sustained impact on HIV-1 incidence: final results of an open-label extension trial of the dapivirine vaginal ring. In: 10th IAS Conference on HIV Science (IAS 2019); Accessed July 10, 2020; W Sussex, England. https://www.nih.gov/news-events/news-releases/mostwomen-use-vaginal-ring-hiv-prevention-open-label-study.

59. Levin J HIV incidence and adherence in DREAM - an open-label trial of dapivirine vaginal ring - 2016/2018. In: Conference on Retroviruses and Opportunistic Infections (CROI).

60. Nel A. Safety, adherence and HIV-1 seroconversion in DREAM - an open-label dapivirine vaginal ring trial. Slides presented at: SA AIDS Conference; June 11-14, 2019; Durban, South Africa. https://www. saaids.co.za/.cm4all/uproc.php/0/Ha11\%201/Hall\%201/Dr\% 20Annalene $\% 20$ Nel.pdf?cdp $=a \& \_=16 b d 6 b f 1740$. Accessed February 10,2020

61. National Institute of Allergy and Infectious Diseases (NIAID). Evaluating the safety of and adherence to a vaginal matrix ring containing dapivirine and oral emtricitabine/tenofovir disoproxil fumarate in an adolescent and young adult female population. Available from: https://aidsinfo.nih.gov/clinical-trials/details/ NCT03593655. Accessed February 7, 2020.

62. National Institute of Allergy and Infectious Diseases. Evaluating the safety and efficacy of the VRC01 antibody in reducing acquisition of HIV-1 infection among men and transgender persons who have sex with men. Available from: https://clinicaltrials.gov/ct $2 /$ show/ NCT02716675. Accessed February 7, 2020.
63. Crowell TA, Colby DJ, Pinyakorn S, et al. Safety and efficacy of VRC01 broadly neutralising antibodies in adults with acutely treated HIV (RV397): a phase 2, randomised, double-blind, placebo-controlled trial. Lancet HIV. 2019;6(5):e297-e306. doi:10.1016/S2352-3018(19) 30053-0

64. Johnson LM, Krovi SA, Li L, et al. Characterization of a reservoir-style implant for sustained release of tenofovir alafenamide (TAF) for HIV Pre-Exposure Prophylaxis (PrEP). Pharmaceutics. 2019;11(7):315. doi:10.3390/pharmaceutics 11070315

65. Gatto G, Girouard N, Brand RM et al. Pharmacokinetics of tenofovir alafenamide by subcutaneous implant for HIV PrEP. In: Conference on Retroviruses and Opportunistic Infections (CROI); Accessed July 10, 2020; Boston, MA. http://www.croiconference.org/sessions/phar macokinetics-tenofovir-alafenamide-subcutaneous-implant-hiv-prep.

66. Immediate or deferred Pre-exposure Prophylaxis for HIV prevention: safe options for pregnant and lactating women (PrEP). ClinicalTrials gov identifier: NCT03227731. Available from: https://clinicaltrials. gov/ct2/show/NCT03227731. Accessed February 3, 2020.

67. Expanded PrEP implementation in communities in NSW (EPIC-NSW). ClinicalTrials.gov identifier: NCT02870790. https:// clinicaltrials.gov/ct2/show/NCT02870790. Accessed February 3, 2020 .

HIV/AIDS - Research and Palliative Care

\section{Publish your work in this journal}

HIV/AIDS - Research and Palliative Care is an international, peerreviewed open-access journal focusing on advances in research in HIV, its clinical progression and management options including antiviral treatment, palliative care and public healthcare policies to control viral spread. The manuscript management system is completely online and includes a very quick and fair peer-review system, which is all easy to use. Visit http://www.dovepress.com/testimonials.php to read real quotes from published authors. 